Revista Iberoamericana, Vol. LXIX, Núm. 203, Abril-Junio 2003, 367-387

\title{
IDENTIDAD, TECNICIDAD, ALTERIDAD APUNTES PARA RE-TRAZAR EL MAPA NOCTURNO DE NUESTRAS CULTURAS
}

POR

Jesús Martín-Barbero

ITESO, Guadalajara, México

El curso que ha tomado el mundo después de los acontecimientos del martes negro, el 11S*, han introducido procesos que amenazan aún más el ya oscuro horizonte de los pueblos latinoamericanos. Empujadas a la recesión económica, la ingobernabilidad política y el desenraizamiento cultural por la implacable lógica de la globalización mercantil, nuestras naciones padecen también la más arcaica peste del miedo que fundamentaliza la seguridad convirtiendo todas las fronteras y las vías de comunicación — terrestres y aéreas, físicas y virtuales - en lugares de legitimación de la desconfianza como método y la violación de los derechos a la privacidad y la libertad civil como comportamiento oficial de las “autoridades", con el consiguiente afianzamiento de los prejuicios raciales, los apartheid étnicos y los fanatismos religiosos. Al fluir tan de prisa como las transacciones financieras, los virus imaginarios amenazan ahora al orden global que reacciona rearmando las fronteras y tornando cada día más sospechoso de enemigo de ese orden al flujo migratorio de las muchedumbres que él mismo empuja desde las periferias pauperizadas hacia los países del próspero, pero ahora, desubicado y desconcertado centro. Al mismo tiempo, las figuras nacionales de nuestros países se emborronan hasta desfigurarse. Ahí está Argentina, pasando de la destrucción sistemática de la memoria nacional político-cultural y sus instituciones por las dictaduras militares de mediados de los años 70, la hiperinflación de los 80 que desquició de sus mínimos ejes tanto la vida personal como colectiva, y el neoliberalismo más puro y duro en los 90 que desmontó los últimos residuos del Estado social precipitando al país a la más brutal depresión económica y la más honda desmoralización. Entretejido a esa debacle está el paso de una identidad nacional argentina configurada, según Beatriz Sarlo, por el ser alfabetizado, ser ciudadano y tener trabajo, al desmantelamiento político y cultural de esa identidad, con las implicaciones morales y políticas que entraña esa implosión de lo social en la que se disuelven "las razones de pertenencia a una sociedad nacional, la idea de responsabilidad que, aun precariamente, tejía la trama de los muchos hilos que sostienen a una comunidad” (Sarlo 28).

Pero también lo acontecido en ese cada día más significativo territorio del periférico sur, que es Porto Alegre, nos obliga a rehacer la reflexión sobre la globalización. El

(*) El autor se refiere al 11 de septiembre de 2001. 
segundo Foro Social Mundial en Porto Alegre se ha convertido en ese extraño escenario en el que, frente al tramposo y excluyente mundo de la economía financiera, hace su aparición en la escena global el mundo de la política, o mejor, la utopía política de un mundo de los ciudadanos y los pueblos. Y en el que justamente este año tanto la comunicación como la educación han pasado a tener una presencia no meramente temática sino articuladora, estratégica.

Si la educación debe ser, según la lógica globalizadora del mercado que proclaman e imponen los organismos económicos mundiales — la OMC, el FMI y el BM-, concebida y organizada en función del mercado de trabajo, — ya que lo que en ella cuenta es la acumulación de capital humano medido en términos de costo/beneficio como cualquier otro capital, la comunicación es planteada en Porto Alegre como el lugar de una doble perversión; primera, la que proviene de la conformación de unas megacorporaciones globales —ya son sólo siete las que dominan el mercado mundial: AOL-Time Warner, Disney, Sony, News Corporation, Viacom y Bertelsmann — cuya concentración económica se traduce en un poder cada día más inatajable de fusión de los dos componentes estratégicos, los vehículos y los contenidos, con la consiguiente capacidad de control de la opinión pública mundial y la imposición de moldes estéticos cada día más "baratos”; segunda, la que han introducido los acontecimientos del “11 S" enrareciendo con controles y amenazas las libertades de información y expresión hasta el punto de poner en serios riesgos los más elementales derechos civiles. Pero la comunicación aparece también en Porto Alegre como lugar de dos estratégicas oportunidades: primera, la que abre la digitalización posibilitando la puesta en un lenguaje común de datos, textos, sonidos, imágenes, videos, desmontando la hegemonía racionalista del dualismo que hasta ahora oponía lo inteligible a lo sensible y lo emocional, la razón a la imaginación, la ciencia al arte, y también la cultura a la técnica y el libro a los medios audiovisuales; segunda: la configuración de un nuevo espacio público y de ciudadanía en y desde las redes de movimientos sociales y de medios comunitarios, como el espacio y la ciudadanía que ha hecho posible, sostiene y conforma, el Foro Mundial. Es obvio que se trata de embriones de una nueva ciudadanía y un nuevo espacio público, configurados por una enorme pluralidad de actores y de lecturas críticas que convergen sobre un compromiso emancipador y una cultura política en la que la resistencia es al mismo tiempo forjadora de alternativas.

I. LA MEDIACIÓN TECNOLÓGICA DEL CONOCIMIENTO EN LA PRODUCCIÓN SOCIAL

Lo que está cambiando no es el tipo de actividades en las que participa la humanidad sino su capacidad de utilizar como fuerza productiva lo que distingue a nuestra especie como rareza biológica, su capacidad de procesar símbolos.

Manuel Castells

Dos procesos están transformando radicalmente el lugar de la cultura en nuestras sociedades de fin de siglo: la revitalización de las identidades y la revolución de las tecnicidades. Los procesos de globalización económica e informacional están reavivando 
la cuestión de las identidades culturales —étnicas, raciales, locales, regionales— hasta el punto de convertirlas en dimensión protagónica de muchos de los más feroces y complejos conflictos internacionales de los últimos años, al tiempo que esas mismas identidades, más las de género y las de edad, están reconfigurando la fuerza y el sentido de los lazos sociales, y las posibilidades de convivencia en lo nacional y aun en lo local. Por su parte, lo que la revolución tecnológica de este fin de siglo introduce en nuestras sociedades no es tanto una cantidad inusitada de nuevas máquinas, sino un nuevo modo de relación entre los procesos simbólicos — que constituyen lo cultural—y las formas de producción y distribución de los bienes y servicios: un nuevo modo de producir, inextricablemente asociado a un nuevo modo de comunicar, convierte al conocimiento en una fuerza productiva directa.

El lugar de la cultura en la sociedad cambia cuando la mediación tecnológica (Echeverría) de la comunicación deja de ser meramente instrumental para espesarse, densificarse y convertirse en estructural: la tecnología remite hoy no a unos aparatos sino a nuevos modos de percepción y de lenguaje, a nuevas sensibilidades y escrituras. Radicalizando la experiencia de desanclaje producida por la modernidad, la tecnología deslocaliza, los saberes, modificando tanto el estatuto cognitivo como institucional de las condiciones del saber y las figuras de la razón (Chartron, Renaud) lo que está conduciendo a un fuerte emborronamiento de las fronteras entre razón e imaginación, saber e información, naturaleza y artificio, arte y ciencia, saber experto y experiencia profana.

Al mismo tiempo afrontamos una perversión del sentido de las demandas socioculturales que encuentran de algún modo expresión en los medios, mediante lo cual se deslegitima cualquier cuestionamiento de un orden social al que sólo el mercado y las tecnologías permitirían dar forma. Esta concepción hegemónica nos sumerge en una creciente oleada de fatalismo tecnológico frente al cual resulta más necesario que nunca mantener la epistemológica y la políticamente estratégica tensión entre las mediaciones históricas que, dotan de sentido y alcance social a los medios, y el papel de mediadores que ellos están jugando hoy. Sin ese mínimo de distancia —o negatividad como dirían los de Frankfurt— nos es imposible el pensamiento crítico.

\section{Peculiaridades latinoamericanas de la sociedad del conocimiento}

Nuestras sociedades son contemporáneas del proceso que constata Manuel Castells, pero son al mismo tiempo "sociedades del des-conocimiento", esto es, del no reconocimiento de la pluralidad de saberes y competencias culturales que, siendo compartidas por las mayorías populares o las minorías indígenas o regionales, no están siendo incorporadas como tales ni a los mapas de la sociedad ni a los sistemas educativos. $\mathrm{Y}$, sin embargo, la subordinación de los saberes orales y visuales al orden de la letra sufre actualmente una erosión creciente e imprevista que se origina en los nuevos modos de producción y circulación de saberes y las nuevas escrituras que emergen a través de las nuevas tecnicidades, y especialmente del computador e Internet. Con raras excepciones, nuestras universidades siguen sin darse por enteradas de las estratégicas relaciones entre aquellos saberes y estas tecnologías (Braganca y Cruz), del mismo modo que desconocen la complejidad de las relaciones que se entrecruzan hoy entre los cambios del saber en la sociedad del conocimiento y los cambios del trabajo en la sociedad de mercado. Esto 
limita su papel para analizar tendencias - las que ponen el mercado y el desarrollo tecnológico en la globalización socioeconómica y en la mundialización de la cultura-, para ver cómo se adapta a ellas, sin el menor esfuerzo ni proyecto de asumir como tarea propia, estructural y estratégica hoy más que nunca, la de formular y diseñar proyectos sociales, la de pensar alternativas al modelo hegemónico del mercado y de la comunicación.

Por otra parte, la noción de sociedad de la información se halla lastrada en nuestros países de una fuerte complicidad discursiva con la modernización neoliberal, racionalizadora del mercado como único principio organizador de la sociedad en su conjunto, según el cual, agotado el motor de la lucha de clases, la historia habría encontrado su recambio en los avatares de la información. La centralidad que las tecnologías ocupan en esa concepción de la sociedad resulta desproporcionada y paradójica en países en los que el crecimiento de la desigualdad atomiza las sociedades deteriorando sus dispositivos de comunicación, esto es de cohesión cultural y política: “desgastadas las representaciones simbólicas, no logramos hacernos una imagen del país que queremos, y por ende, la política no logra fijar el rumbo de los cambios en marcha” (Lechner 1995 133). De ahí el ensanchamiento de la brecha y la desmoralización colectiva: nuestras gentes pueden asimilar con cierta facilidad las imágenes de la modernización que proponen los cambios tecnológicos pero es a otro ritmo, mucho más lento y doloroso, que pueden recomponer sus sistemas de valores, de normas éticas y virtudes cívicas.

\section{Un entorno de saberes difuso y descentrado}

Vivimos en un entorno de información que recubre y entremezcla saberes múltiples y formas muy diversas de aprender, a la vez que se halla fuertemente descentrado en relación con el sistema educativo que aún nos rige, organizado en torno a la escuela y el libro. Desde los monasterios medievales hasta las escuelas de hoy, el saber ha conservado ese doble carácter de estar a la vez centralizado y personificado en figuras sociales determinadas. De ahí que una transformación en los modos de circulación del saber (Rifkin, Fischer), como la que estamos viviendo, es una de las más profundas transformaciones que puede sufrir una sociedad. Puesto que es disperso y fragmentado como el saber, puede circular por fuera de los lugares sagrados que antes lo detentaban y de las figuras sociales que lo administraban. La escuela está dejando de ser el único lugar de legitimación del saber, ya que hay una multiplicidad de saberes que circulan por otros canales, difusos y descentralizados. Esta diversificación y difusión del saber, por fuera de la escuela, es uno de los retos más fuertes que el mundo de la comunicación le plantea al sistema educativo. Saberes-mosaico, como los ha llamado Abraham Moles, por estar hechos de trozos, de fragmentos, que sin embargo no impiden a los jóvenes tener con frecuencia un conocimiento más actualizado en física o en geografía que su propio maestro. Esto está acarreando en la escuela no una apertura a esos nuevos saberes, sino una puesta a la defensiva y la construcción de una idea negativa y moralista de todo lo que viene del ecosistema comunicativo de los medios y las tecnologías de comunicación e información.

Por un lado, los nuevos saberes remiten a nuevas figuras de razón que nos interpelan desde la tecnicidad. Con el computador estamos no ante una máquina con la que se 
producen objetos sino ante un nuevo tipo de tecnicidad que posibilita el procesamiento de informaciones y cuya materia prima son abstracciones y símbolos, lo que inaugura una nueva aleación de cerebro e información que sustituye la relación tradicional del cuerpo con la máquina. Del otrolado, las redes informáticas, al transformar nuestra relación con el espacio y el lugar, movilizan figuras de un saber que escapa a la razón dualista con la que estamos habituados a pensar la técnica (Broncano), pues se trata de movimientos que son a la vez de integración y de exclusión, de desterritorialización y de relocalización, nicho en el que interactúan y se entremezclan lógicas y temporalidades tan diversas como las que entrelazan en el hipertexto las sonoridades del relato oral con las intertextualidades de la escritura y las intermedialidades del audiovisual. Una de las más claras señales de la hondura del cambio en las relaciones entre cultura, tecnología y comunicación se halla en la reintegración cultural de la dimensión separada y minusvalorada por la racionalidad dominante de Occidente desde la invención de la escritura y el discurso lógico, esto es la del mundo de los sonidos y las imágenes relegado al ámbito de las emociones y las expresiones. Al trabajar interactivamente con sonidos, imágenes y textos escritos, el hipertexto hibrida la densidad simbólica con la abstracción numérica, haciendo que se encuentren las dos partes del cerebro, hasta ahora “opuestas” (Varela, Thompson, Gardini y Rosch). De ahí que de mediador universal del saber, el número esté pasando a ser mediación técnica del hacer estético, lo que a su vez revela el paso de la primacía sensoriomotriz a la sensorio-simbólica.

\section{Cambios en los mapas laborales y profesionales}

Aunque nuestras universidades no parecen darse por enteradas, está en marcha una transformación en profundidad del mapa “moderno" de las profesiones y la emergencia de otro mapa ligado cada día más a la configuración de los nuevos oficios que vienen exigidos por nuevas formas del producir, del comunicar y del gestionar, ligados tanto a las nuevas destrezas mentales que introduce la alfabetización al mundo laboral como a los nuevos modelos empresariales. Estamos, en primer lugar, ante un nuevo estatuto social del trabajador (Sennet, Beck) que si bien implica el paso de un trabajo caracterizado por la ejecución mecánica de tareas repetitivas al de un trabajo con un mayor componente de iniciativa por parte del trabajador, al desplazar el ejercicio de la predominancia de la mano a la del cerebro mediante nuevos modos del hacer, que exigen un saber-hacer, un despliegue de destrezas con un mayor componente mental, ello no significa la liberación de la iniciativa del trabajador, de su capacidad de innovación y creatividad, sino su control por la lógica de la rentabilidad empresarial que la supedita en todo momento a la "evaluación de los resultados”. Al mismo tiempo, esa llamada flexibilidad oculta su verdadera realidad: la precarización del empleo en términos de la duración del contrato de trabajo tanto como en las prestaciones salariales en salud, pensión, educación, vacaciones, etc. Sometido a la férrea lógica de la competitividad, el trabajo sufre una fuerte mengua, y hasta la desaparición del vínculo societal — espacial y temporal - entre el trabajador y la empresa, afectandose profundamente la estabilidad psíquica del trabajador: al dejar de ser un ámbito clave de comunicación social, de reconocimiento social de sí 
mismo, el trabajo pierde también su capacidad de ser un lugar central de significación del vivir personal, del sentido de la vida (Dubar).

Cambia también la figura del profesional, convertida en el lugar propio de la nueva complejidad de relaciones entre los cambios del saber en la sociedad de conocimiento y los cambios del trabajo en una sociedad de mercado. La nueva figura remite, en primer lugar, a los grupos/proyecto, los "círculos de calidad” en los que cada individuo compite con los otros individuos del grupo, y cada grupo compite con otros grupos, no sólo fuera sino incluso dentro de la misma empresa. Las condiciones de competitividad entre todos se traducen en la fragmentación tanto del oficio como de las comunidades de oficio. Los nuevos modelos de empresa hacen así imposible el largo tiempo, tanto en el sentido de la pertenencia a una colectividad empresarial, como en el de la carrera profesional. También el nivel salarial tiene cada vez menos que ver con los años de trabajo en la empresa: hoy profesionales que llevan muchos años en una empresa son sustituidos por jóvenes recién llegados que además entran a trabajar ganando el doble del sueldo de los antiguos. El nuevo profesional es un individuo abocado a la permanente reconversión de sí mismo, y ello en un momento en el cual todo en la sociedad hace del individuo un sujeto inseguro, lleno de incertidumbre, con muy fuertes tendencias a la depresión, al estrés afectivo y mental. Divorciado del largo plazo que implicaba la vida profesional, y del largo tiempo de la solidaridad laboral, no sólo el valor sino también el sentido del trabajo profesional pasa a ligarse a una creatividad y a una flexibilidad unidas a la lógica mercantil de la competitividad que enlaza inextricablemente saber y rentabilidad.

II. LA EXPLOSIÓN DE LAS IDENTIDADES

\begin{abstract}
La comprensión de la identidad en la sociedad contemporánea resulta de la aplicación de una doble perspectiva de figuras que no se acumulan sino que presentan tensiones: la reflexión sobre la crisis de las formas de comunicación discursiva como lugar principal de la identidad presente, $y$ la necesidad imperiosa de construir discursos de experiencia que suturen los déficits de legitimación en los discursos anónimos que nos son dirigidos. José Miguel Marinas
\end{abstract}

Ligado a sus dimensiones tecno-económicas, la globalización pone en marcha un proceso de interconexión mundial, que conecta todo lo que instrumentalmente vale empresas, instituciones, individuos - al mismo tiempo que desconecta todo lo que, para esa razón, no vale (Bauman). Este proceso de inclusión/exclusión planetario está produciendo no sólo reacciones y atrincheramientos, sino una disyunción profunda y creciente entre la lógica de lo global y las dinámicas de lo local, entre el espacio de la economía política y los modos de vida. La manifestación más visible y honda de esa disyunción es la presencia en la experiencia cotidiana de la gente de un sentimiento 
compartido de impotencia, es decir que su trabajo, su entorno y su propia vida escapan aceleradamente de su control. Al entrar en crisis las tres grandes instituciones de la modernidad — el trabajo, la política y la escuela— que constituían la fuente del sentido colectivo de la vida, su significado se divorcia de lo que el individuo o la comunidad hace para ligarse a lo que se es: hombre o mujer, negro o blanco, cristiano o musulmán, indígena o mestizo. La sociedad-red no es un puro fenómeno de conexiones tecnológicas, sino la disyunción sistémica de lo global y lo local, de lo público-formal y lo privado-real (Appadurai), mediante la fractura de sus marcos temporales de experiencia y de poder: frente a la élite que habita el espacio atemporal de las redes y los flujos globales, las mayorías en nuestros países habitan el dislocado espacio/tiempo local de sus culturas, y frente a la lógica del poder global se refugian en la lógica del poder que produce la identidad. Estamos así ante una mutación, en los inicios de un verdadero cambio de época, que nos aboca a investigar las siguientes cuestiones:

\section{Los cambios de fondo en la percepción y el sentido de las identidades}

Si Habermas constata el descentramiento que sufren las sociedades complejas por la ausencia de una instancia central —Estado, Iglesia— de regulación y autoexpresión en la que "hasta las identidades colectivas están sometidas a la oscilación en el flujo de las interpretaciones ajustándose más a la imagen de una red frágil que a la de un centro estable de autorreflexión” (1990 424), Stuart Hall hace explícita la fragilización de aquello que suponíamos fijo y la desestabilización de lo que creíamos uno: "Un tipo nuevo de cambio estructural está fragmentando los paisajes culturales de clase, género, etnia, raza y nacionalidad, que en el pasado nos habían proporcionado sólidas localizaciones como individuos sociales. Transformaciones que están también cambiando nuestras identidades personales” (1999 16). El cambio apunta especialmente a la multiplicación de referentes desde los que el sujeto se identifica en cuanto tal, pues el descentramiento no lo es sólo de la sociedad sino de los individuos, que ahora viven una integración parcial y precaria de las múltiples dimensiones/adscripciones que los conforman. El individuo ya no es lo indivisible, y cualquier unidad que se postule tiene mucho de "unidad imaginada”. Pero eso no puede ser confundido con la celebración de la diferencia convertida en fragmentación, proclamada por buena parte del discurso posmoderno y rentabilizada por el mercado. La celebración de las identidades débiles (fragmentadas) tiene una fuerte relación con otra celebración, la de la des-regulación del mercado, exigida por la ideología neoliberal de la que David Harvey explicita la paradoja: "cuanto menos decisivas se tornan las barreras espaciales tanto mayor es la sensibilidad del capital hacia las diferencias del lugar y tanto mayor el incentivo para que los lugares se esfuercen por diferenciarse como forma de atraer el capital” (1989 296). La identidad local es obligada así a convertirse en una representación de la diferencia que la hace comercializable, es decir, sometida a los maquillajes que refuerzan su exoticidad y a las hibridaciones que neutralizan sus rasgos más conflictivos. Es la otra cara de la globalización, acelerando las operaciones de desarraigo con que intenta inscribir las identidades en las lógicas de los flujos: dispositivo de traducción de todas las diferencias culturales a la lengua franca del mundo tecno-financiero y la 
volatilización de las identidades para que floten libremente en el vacío moral y la indiferencia cultural.

Hasta hace poco, decir identidad era hablar de raíces, esto es, de raigambre y territorio, de tiempo largo y de memoria simbólicamente densa. De eso y solamente de eso estaba hecha la identidad. Pero decir identidad hoy implica también —si no queremos condenarla al limbo de una tradición desconectada de las mutaciones perceptivas y expresivas del presente- hablar de migraciones y movilidades, de redes y de flujos, de instantaneidad y desanclaje. Antropólogos ingleses han expresado esa nueva conformación de las identidades a través de la espléndida imagen de las moving roots, raíces móviles o, mejor, de raíces en movimiento. Para mucho del imaginario sustancialista y dualista que todavía permea la antropología, la sociología y hasta la historia, esa metáfora resultará inaceptable, y sin embargo, en ella se vislumbra alguna de las realidades más fecundamente desconcertantes del mundo que habitamos: como afirma el antropólogo catalán, Eduard Delgado, “sin raíces no se puede vivir pero muchas raíces impiden caminar”. Así, la diversidad cultural se hace interculturalidad en los territorios y las memorias pero también desde las redes la diversidad resiste, enfrenta e interactúa con la globalización, y acabará por transformarla (Sosoe). Desde ahí es que hoy se proyectan búsquedas de alternativas, comunitarias y libertarias, capaces incluso de revertir el sentido mayoritariamente excluyente que las redes tecnológicas tienen para las mayorías, transformándolas en potencial de enriquecimiento social y personal.

\section{Globalización: entre identidades y flujos}

Acelerando las operaciones de desarraigo, la globalización tiende a inscribir las identidades en las lógicas de los flujos: dispositivo de traducción de todas las diferencias culturales a la lengua franca del mundo tecno-financiero y volatilización de las identidades para que floten libremente en el vacío moral y la indiferencia cultural (Klein, Bonin). La complementariedad de movimientos en que se basa esa traidora traducción no puede ser más expresiva: mientras el movimiento de las imágenes y las mercancías va del centro a la periferia, el de los millones de emigrantes objeto de exclusión va de la periferia al centro. Con la consiguiente reidentificación - frecuentemente fundamentalista — de las culturas de origen que se produce en los “enclaves étnicos” que parchean las grandes ciudades de los países del norte. La globalización exaspera y alucina a las identidades básicas, a las identidades que echan sus raíces en los tiempos largos. Lo que hemos visto en Sarajevo y Kosovo, es eso: una alucinación de las identidades que luchan por ser reconocidas pero cuyo reconocimiento sólo es completo cuando expulsan de su territorio a todos los otros y se encierran sobre sí mismos. Pero la exasperación de las identidades no ocurre sólo al otro lado del globo, la reencontramos también en la intolerancia con la que en Argentina o Chile son hoy excluidos, por los propios sectores obreros, los migrantes provenientes de Bolivia o Paraguay (Grimson). Como si al caerse las fronteras, que durante siglos demarcaron los diversos mundos, las distintas ideologías políticas, los diferentes universos culturales — por acción conjunta de la lógica tecno-económica y la presión migratoriahubieran quedado al descubierto las contradicciones del discurso universalista, del que tan orgulloso se ha sentido Occidente. Entonces cada cual, cada país o comunidad de países, 
cada grupo social y hasta cada individuo, necesitará conjurar la amenaza que significa la cercanía del otro, de los otros, en todas sus formas y figuras, rehaciendo la exclusión ahora ya no bajo la forma de fronteras, que serían obstáculo al flujo de las mercancías y las informaciones, sino de distancias que vuelvan a poner "a cada cual en su sitio".

Pero el revival identitario presenta un carácter especialmente ambiguo y hasta contradictorio, pues en él habla no sólo la revancha de identidades negadas o no reconocidas, sino que ahí se abren camino también las voces alzadas contra viejas exclusiones. Si en el inicio de muchos movimientos identitarios el auto-reconocimiento es reacción al aislamiento, también lo es su funcionamiento como espacio de memoria y solidaridad, y como lugar de refugio en el que los individuos encuentran una tradición moral (Bellah). Los nacionalismos, las xenofobias o los fundamentalismos religiosos no se agotan en lo cultural, pues todos ellos remiten, en periodos más o menos largos de su historia, a exclusiones sociales y políticas, a desigualdades e injusticias acumuladas, sedimentadas. Pero lo que galvaniza hoy a las identidades como motor de lucha es inseparable de la demanda de reconocimiento y de sentido. Ni el uno ni el otro son formulables en meros términos económicos o políticos, pues ambos se hallan referidos al núcleo mismo de la cultura, en cuanto mundo del pertenecer a y del compartir con. Razón por la cual la identidad se constituye hoy en la negación más destructiva, pero también más activa y capaz de introducir contradicciones en la hegemonía de la razón instrumental.

\section{El carácter constitutivo de las narrativas identitarias}

La relación de la narración con la identidad es constitutiva: no hay identidad cultural que no sea contada (Marinas, Bhabha). Esa relación entre narratividad y reconocimiento de la identidad se hace preciosamente visible en la polisemia castellana del verbo contar cuando nos referimos a los derechos de las culturas, tanto de las minorías como de los pueblos. Pues para que la pluralidad de las culturas del mundo sea políticamente tenida en cuenta, es indispensable que la diversidad de las identidades nos pueda ser contada. Narrada en cada uno de los idiomas y al mismo tiempo en el lenguaje multimedial en que hoy se juega el movimiento de las traducciones — de lo oral a lo escrito, de lo audiovisual a lo informático—, y en ese otro aún más complejo y ambiguo: el de las apropiaciones y los mestizajes. En su sentido más denso y desafiante la idea de la multiculturalidad apunta ahí: a una interculturalidad en la que las dinámicas de la economía y la cultura-mundo movilizan no sólo la heterogeneidad de los grupos y su readecuación a las presiones de lo global, sino la coexistencia al interior de una misma sociedad de códigos y relatos muy diversos, conmocionando así la experiencia que hasta ahora teníamos de la identidad. Lo que la globalización pone en juego no es sólo una mayor circulación de productos sino una rearticulación profunda de las relaciones entre culturas y entre países, mediante una descentralización que concentra el poder económico y una des-territorialización que hibrida las culturas.

Esa hibridación penetra también el campo de los relatos, pues la mayoría de ellos sobreviven inscritos en el ecosistema discursivo de los medios y son colonizados por la racionalidad operativa del dispositivo y el saber tecnológicos. Es en ese ecosistema y esos dispositivos donde se juega — se hace y deshace- la diferencia entre unos géneros cuyo 
estatuto ha dejado de ser puramente literario para tornarse cultural; esto es cuestión de memoria y reconocimiento, frente a unos formatos en los que habla el sistema productivo, las lógicas de una comunicabilidad crecientemente se subordinan a la rentabilidad. Momentos de una negociación entre las reglas de construcción del texto y las competencias del lector, los géneros remiten a su reconocimiento en y por una comunidad cultural, pues aun adelgazados por el largo transcurso que los separa de los relatos arquetípicos, los géneros conservan aún cierta densidad simbólica. Los formatos, en cambio, funcionan como operadores de una combinatoria sin contenido, estrategia puramente sintáctica. Pero la subordinación de los géneros a la lógica de los formatos remite, más allá de las condiciones en que operan las industrias culturales, al oscurecimiento de una tradición cuyos relatos - y metarrelatos_ posibilitaban la inserción del presente en las memorias del pasado y en los proyectos de futuro. Roto ese engarce, la crisis de la estética de la obra y del autor halla su más certera expresión en la proliferación/fragmentación de los relatos. Como si extraviada su fuente, la narración hubiera estallado en pedazos, asistimos a la multiplicación infinita de unos microrrelatos que se gestan en cualquier parte y se desplazan de unos medios a otros (Sánchez-Biosca).

\title{
III. HeTEROGENEIDADES SOCIOCULTURALES
}

\begin{abstract}
Si es a través de la imaginación que hoy el capitalismo disciplina y controla a los ciudadanos contemporáneos, sobre todo a través de los medios de comunicación, es también la imaginación la facultad a través de la cual emergen nuevos patrones colectivos de disenso, de desafección y cuestionamiento de los patrones impuestos a la vida cotidiana; a través de la cual vemos emerger formas sociales nuevas, no predatorias como las del capital, formas constructoras de nuevas convivencias humanas.
\end{abstract}

Arjun Appadurai

Así como las identidades implosionan fundamentalizándose, también explosionan reinventándose en proyectos de radical renovación de la política y la sociedad toda. Me refiero a la creciente presencia de estrategias tanto de exclusión como, y especialmente, de empoderamiento ejercidas en y desde el ámbito de la cultura (Appadurai). Estas últimas no sólo inscriben las “políticas de identidad” dentro de la política de emancipación humana, sino que replantean a fondo el sentido mismo de la política, postulando el surgimiento de un nuevo tipo de sujeto político. Sujeto entrevisto desde que el feminismo subvirtiera el machismo metafísico de las izquierdas con "lo personal es político”, y que en los últimos años incorpora en el mismo movimiento el sentimiento de daño/victimación y el de reconocimiento/empoderamiento. Sentimiento este último que recupera para el proceso de construcción identitaria tanto lo que se disputa de poder y pasa por el ámbito 
de los imaginarios, como lo que se produce en la materialidad de las relaciones sociales. La afirmación de una subjetividad fracturada y descentrada, así como la multiplicidad de identidades en pugna, aparece por primera vez en el feminismo no como postulado teórico sino como resultado de la exploración de la propia experiencia de la opresión (Mouffe).

\section{Nuevas figuras de la ciudadanía}

Las nuevas figuras ciudadanas remiten, de un lado, a políticas del reconocimiento que, según Charles Taylor, hallan su base en la modernidad política donde se aloja "la idea de que el pueblo cuenta con una identidad anterior a alguna estructuración política" (Taylor 1998; ver también Fraser 1998). La idea de reconocimiento se juega en la distinción entre el "honor" tradicional, como concepto y principio jerárquico, y la “dignidad” moderna como principio igualitario. La identidad no es pues lo que se le atribuye a alguien por el hecho de estar aglutinado en un grupo — como en la sociedad de castas - sino la expresión de lo que da sentido y valor a la vida del individuo. Es al tornarse expresiva de un sujeto individual o colectivo que la identidad depende, y por lo tanto vive del reconocimiento de los otros: la identidad se construye en el diálogo y el intercambio, ya que es ahí donde los individuos y los grupos se sienten despreciados o reconocidos por los demás. Las identidades/ciudadanías modernas — al contrario de aquellas que eran algo atribuido a partir de una estructura preexistente como la nobleza o la plebe- se construyen en la negociación del reconocimiento por los otros. Por otro lado, lo que el multiculturalismo pone en evidencia es que las instituciones liberal-democráticas se han quedado estrechas (Mouffe, Laclau) para acoger las múltiples figuras de la diversidad cultural que tensionan y desgarran nuestras sociedades justamente porque no caben en esa institucionalidad. Desgarradura que sólo puede ser suturada con una política de extensión de los derechos y valores universales frente a todos los sectores de la población que han vivido por fuera de la aplicación de esos derechos, sean mujeres o minorías étnicas, evangélicos u homosexuales. Estamos en todo nuestro derecho a negarnos a tener que escoger entre el universalismo heredado de la Ilustración, que dejaba de lado sectores enteros de la población, y un diferencialismo tribal que se afirma en la exclusión racista y xenófoba, pues esa disyuntiva es mortal para la democracia (Wieviorka). Frente a la ciudadanía de "los modernos" que se pensaba y se ejercía por encima de las identidades de género, de etnia, de raza o de edad, la democracia está necesitada hoy de una ciudadanía que se haga cargo de las identidades y las diferencias, pues la democracia se convierte hoy en escenario de la emancipación social y política cuando nos exige sostener la tensión entre nuestra identidad como individuos y como ciudadanos, y sólo a partir de esa tensión se hará posible sostener colectivamente la otra, la tensión entre diferencia y equivalencia (igualdad). Y saldremos, entonces, de la ilusoria búsqueda de una reabsorción de la alteridad en un todo unificado, sea éste la nación, el partido o la religión. Emergen entonces, o pasan al primer plano, derechos de ciudadanía vinculados a las diversas comunidades culturales que conforman una nación desde la doble perspectiva, tanto de su construcción jurídica como ética, esto es desde el nuevo valor de la diferencia que articula la universalidad humana de los derechos a la particularidad de los muy diversos modos de su percepción y expresión. Es la línea de la ética de la comunicación (Habermas, Vattimo) caracterizada 
por jugarse mucho menos en certezas y absolutización de valores que en posibilidades de encuentro y de lucha contra la exclusión social, política y cultural, de la que son objeto en nuestros países tanto las mayorías pobres como las minorías étnicas o sexuales. En la experiencia de desarraigo que viven tantas de nuestras gentes, a medio camino entre el universo campesino y un mundo urbano cuya racionalidad económica e informativa disuelve sus saberes y su moral, devalúa su memoria y sus rituales; hablar de reconocimiento implica un doble campo básico de derechos a impulsar: el derecho a la participación en cuanto capacidad de las comunidades y los ciudadanos a la intervención en las decisiones que afectan su vivir, capacidad que se halla hoy estrechamente ligada a una información veraz y en la que predomina el interés común sobre el del negocio; y segundo, el derecho a la expresión en los medios masivos y comunitarios de todas aquellas culturas y sensibilidades mayoritarias o minoritarias a través de las cuales pasa la ancha y rica diversidad de la que están hechos nuestros países.

\section{Reconfiguraciones de lo público}

La cada vez más estrecha relación entre lo público y lo comunicable —ya presente en el sentido inicial del concepto político de publicidad en la historia trazada por Habermas - se juega hoy decisivamente en la ambigua, y muy cuestionada, mediación de las imágenes que, pasando por las mil formas de afiches y graffitis, desemboca en la televisión, y es casi siempre asociada, o llanamente reducida, a un mal inevitable y a una incurable enfermedad de la política contemporánea, a un vicio proveniente de la decadente democracia norteamericana, o a una concesión a la barbarie de estos tiempos que tapa con imágenes su falta de ideas. Y no es que en el uso que de las imágenes hacen el mercado y la política haya no poco de todo eso, sino que necesitamos comprenderlo más allá de la denuncia, hacia una comprensión de lo que la mediación de las imágenes produce socialmente, único modo de poder intervenir sobre ese proceso. Pues esa hegemonía imagética se halla asociada al hecho de que hoy el "reconocimiento recíproco" (Arendt) se juega especialmente en el derecho a ser visto y oído, que equivale al de existir/contar socialmente, tanto en el terreno individual como en el colectivo, en el de las mayorías como en el de las minorías. Derecho que nada tiene que ver con el exhibicionismo vedetista de los políticos en su perverso afán por sustituir su perdida capacidad de representar lo común por la cantidad de tiempo en pantalla.

Lo que en las imágenes se produce es, en primer lugar, la salida a flote, la emergencia de la crisis que sufre, desde su interior mismo, el discurso de la representación (Flores d'Arcais). Pues si bien es cierto que la creciente presencia de las imágenes en el debate, las campañas y aun en la acción política, espectaculariza ese mundo hasta confundirlo con el de la farándula, los reinados de belleza o las iglesias electrónicas, también es cierto que por las imágenes pasa una construcción visual de lo social en la que esa visibilidad recoge el desplazamiento de la lucha por la representación a la demanda de reconocimiento. Lo que los nuevos movimientos sociales y las minorías — las etnias y las razas, las mujeres, los jóvenes o los homosexuales- demandan no es tanto ser representados sino reconocidos: hacerse visibles socialmente en su diferencia. Lo que da lugar a un modo nuevo de ejercer políticamente sus derechos. Y, en segundo lugar, en las imágenes se produce un profundo 
des-centramiento de la política tanto sobre el sentido de la militancia como en el del discurso partidista. Del fundamentalismo sectario que acompañó, desde el siglo pasado hasta bien entrado el actual, el ejercicio de la militancia tanto en las derechas como en las izquierdas, las imágenes dan cuenta del enfriamiento de la política, con el que Norbert Lechner denomina la desactivación de la rigidez en las pertenencias que posibilita fidelidades más móviles y colectividades más abiertas. En lo que respecta al discurso, la nueva visibilidad social de la política cataliza el desplazamiento del discurso doctrinario, de carácter abiertamente autoritario, a una discursividad si no claramente democrática hecha al menos de ciertos tipos de interacciones e intercambios con otros actores sociales. De ello es evidencia la proliferación creciente de observatorios y veedurías ciudadanas. Resulta significativa esta articulación semántica, más que cercanía fonética, entre la visibilidad de lo social que posibilita la constitutiva presencia de las imágenes en la vida pública y las veedurías como forma actual de fiscalización e intervención de los ciudadanos.

Por otro lado, el vacío de utopías que atraviesa el ámbito de la política se ha llenado en los últimos años de un cúmulo de utopías provenientes del campo de la tecnología y la comunicación: “aldea global”, “mundo virtual”, “ser digital”, etc. Y la más engañosa de todas, la "democracia directa” (Mongin 1996 303-321), que atribuye al poder de las redes informáticas la renovación de la política y la superación, de paso, de las "viejas” formas de la representación por la expresión viva de los ciudadanos, ya sea votando por Internet desde la casa o emitiendo telemáticamente su opinión. Estamos ante la más tramposa de las idealizaciones, ya que en su celebración de la inmediatez y la transparencia de las redes cibernéticas lo que se está minando son los fundamentos mismos de "lo público”, es decir, los procesos de deliberación y de crítica; al mismo tiempo que se crea la ilusión de un proceso sin interpretación ni jerarquía, se fortalece la creencia de que el individuo puede comunicarse prescindiendo de toda mediación social, y se acrecienta la desconfianza hacia cualquier figura de delegación y representación. Hay sin embargo en no pocas de las proclamas y búsquedas de una “democracia directa” vía Internet, un trasfondo libertario que apunta a la desorientación en que vive la ciudadanía como resultado de la ausencia de densidad simbólica y la incapacidad de convocación que padece la política representativa. Trasfondo libertario que señala también la frustración que produce, especialmente entre las mujeres y los jóvenes, la incapacidad de representación de la diferencia en el discurso que denuncia la desigualdad. Devaluando lo que la nación tiene de horizonte cultural común — por su propia incapacidad de articular la heterogeneidad, la pluralidad de diferencias de las que está hecha—, los medios y las redes electrónicas se están constituyendo en mediadores de la trama de imaginarios que configura la identidad de las ciudades y las regiones, del espacio local y barrial, vehiculando así la multiculturalidad que hace estallar los referentes tradicionales de la identidad. Y para los apocalípticos que tanto abundan hoy-, ahí están los usos que de las redes hacen muchas minorías y comunidades marginadas introduciendo ruido en las redes, distorsiones en el discurso de lo global, a través de los cuales emerge la palabra de otros, de muchos otros. Esa vuelta de tuerca que evidencia en las grandes ciudades el uso de las redes electrónicas para construir grupos que, virtuales en su nacimiento, acaban territorializándose, pasando de la conexión al encuentro, y del encuentro a la acción. El uso alternativo de las tecnologías 
y las redes informáticas (Kroes, Finquelievich, Molina) en la reconstrucción de la esfera pública, pasa sin duda por profundos cambios en los mapas mentales, en los lenguajes y los diseños de políticas, exigidos todos ellos por las nuevas formas de complejidad que revisten las reconfiguraciones e hibridaciones de lo público y lo privado. Empezando por la propia complejidad que a ese respecto presenta Internet: un contacto privado entre interlocutores, que es a su vez mediado por el lugar público que constituye la red: proceso que además introduce una verdadera explosión del discurso público al movilizar la más heterogénea cantidad de comunidades, asociaciones y tribus, que al mismo tiempo que liberan las narrativas de lo político desde las múltiples lógicas de los mundos de vida, despotencian el centralismo burocrático de la mayoría de las instituciones potenciando la creatividad social en el diseño de la participación ciudadana.

Las tecnologías no son neutras; hoy más que nunca constituyen enclaves de condensación e interacción de intereses económicos y políticos con mediaciones sociales y conflictos simbólicos. Pero por eso mismo, son constitutivas de los nuevos modos de construir opinión pública y de las nuevas formas de ciudadanía, esto es, de las nuevas condiciones en que se dice y hace la política.

\section{Nuevos regimenes culturales de la tecnicidad}

La verdad es que la imagen no es lo único que ha cambiado. Lo que ha cambiado, más exactamente, son las condiciones de circulación entre lo imaginario individual (por ejemplo, los sueños), lo imaginario colectivo (por ejemplo, el mito) y la ficción (literaria o artística). Tal vez sean las maneras de viajar, de mirar, de encontrarse las que han cambiado, lo cual confirma la hipótesis según la cual la relación global de los seres humanos con lo real se modifica por el efecto de representaciones asociadas con las tecnologías, con la globalización y con la aceleración de la historia.

Marc Augé

La convergencia de la globalización y la revolución tecnológica configura un nuevo ecosistema de lenguajes y escrituras. La experiencia audiovisual trastornada por la revolución digital señala la constitución de nuevas temporalidades ligadas a la compresión de la información, al surgimiento de nuevas figuras de razón que remiten al estatuto cognitivo que la digitalización ha procurado a la imagen y, finalmente la emergencia de una visibilidad cultural convertida en escenario de una decisiva batalla política entre el orden/poder de la letra y las oralidades y visualidades culturales que enlazan las memorias con los imaginarios en el palimpsesto que, a la vez que borra, les permite emerger borrosamente en las entre líneas que escriben el presente, pues los imaginarios de la virtualidad y la velocidad dan forma, borrosa también, al futuro que tejen las redes del hipertexto. 
$>$ DESTIEMPOS Y DESMEMORIAS

Pocos cambios tan desconcertantes como los que afectan nuestra percepción colectiva del tiempo. Mientras unos denuncian exaltadamente la amnesia histórica, otros ostentan la actual "explosión de la memoria”, y otros indican la complementariedad entre ambas actitudes y movimientos. Lo cierto es que no pocas de las denuncias más apocalípticas del milenarismo escapista retroalimentan emborronando la atmósfera cultural e intelectual, ya de por sí confusa y oscura, impidiéndonos analizar la estructura de los cambios que atravesamos. Frente a los escapismos y los alarmismos, necesitamos investigar nuestra contradictoria percepción de las transformaciones de la temporalidad, de modo que podamos "pensar juntos la amnesia y el boom de la memoria” (Huyssen). Pues sí, de un lado los medios masivos se han convertido en "máquinas de producir presente” (Mogin 1994 24), o sea, se hallan dedicados a fabricar olvido - lo que vale como noticia es lo que nos conecta con el presente de lo que está pasando, lo que a su vez hace que el tiempo en pantalla de cualquier acontecimiento deba ser también instantáneo y equivalente, con lo que el presente, convertido en actualidad, dura cada vez menos_-, que es a lo que se halla dedicado el mercado en su conjunto, al planificar la acelerada obsolescencia de los objetos como condición de funcionamiento del propio sistema de producción; por otro lado, la fiebre de memoria es también creciente: el crecimiento y expansión de los museos en las dos últimas décadas, la restauración de los viejos centros urbanos, el auge de la novela histórica y los relatos biográficos, la moda retro en arquitectura y vestidos, el entusiasmo por las conmemoraciones y el auge de los anticuarios.

Pero develando la acción del mercado y los medios no hemos tocado fondo, hay algo aún más abajo: la obsolescencia acelerada y el debilitamiento de nuestros asideros identitarios nos están generando un incontenible deseo de pasado que no se agota en la evasión. Aunque moldeado por el mercado, ese deseo existe y debe ser tomado en serio como síntoma de una profunda desazón cultural, en la que se expresa la ansiosa indigencia que padecemos de tiempos más largos y la materialidad de nuestros cuerpos reclamando menos espacio y más lugar. Todo lo cual nos plantea el desafío radical que ha formulado Huyssen: no oponer maniqueamente la memoria y la amnesia sino pensarlas juntas. Pues si la "fiebre de historia" que denunciara Nietzsche en el siglo xix funcionaba inventando tradiciones nacionales e imperiales, esto es, dando cohesión cultural a sociedades desgarradas por las convulsiones de la revolución industrial, nuestra "fiebre de memoria" no tiene un foco político ni territorial claro, sino que es expresión de la necesidad de anclaje temporal que sufren unas sociedades cuya temporalidad es sacudida brutalmente por la revolución informacional que disuelve las coordenadas espacio-territoriales de nuestras vidas. Y en la que se hace manifiesta la transformación profunda que padece la "estructura de temporalidad" que nos legó la modernidad: aquella que, frente a la conservadora mirada romántica, legitimó ya desde el siglo XviI la destrucción del pasado como lastre, e hizo de la novedad la fuente única de legitimidad cultural.

La experiencia del progreso moderno en la que Walter Benjamin viera un tiempo homogéneo y vacío, es la que Gianni Vattimo devela en la sociedad actual: la renovación permanente e incesante de las cosas, de los productos, de las mercancías, está “fisiológicamente exigida para asegurar la pura y simple supervivencia del sistema”, en la 
que "la novedad nada tiene de revolucionaria ni turbadora" (Vattimo 1986 14). En un mundo en el que el futuro aparece garantizado por los automatismos del sistema, lo único que nos queda de tiempo humano es "el cuidado de los residuos, de las huellas de lo vivido, [pues] lo que corre el riesgo de desaparecer es el pasado como continuidad de la experiencia” (Vattimo 198912 y ss). Continuidad que no se confunde ni con la uniformación ni con la nostalgia, pues se trata del mínimo de horizonte histórico que hace posible el diálogo entre generaciones y la lectura/traducción entre tradiciones.

> DES-ÓRDENES DE LA RAZÓN

El cambio más desconcertante para el racionalismo con que se identificó la primera modernidad, quizá sea el que introduce el nuevo estatuto cognitivo de la imagen. Desde el mito platónico de la caverna, y durante siglos, la imagen fue identificada con la apariencia y la proyección subjetiva, lo que la convertía en obstáculo estructural del conocimiento. Ligada al mundo del engaño, la imagen fue, por un lado, asimilada a un instrumento de manipulación, de persuasión religiosa o política y, por otro, expulsada del campo del conocimiento y confinada al campo del arte. Hoy día nuevas formas de articular la observación y la abstracción, basadas en el procesamiento — digitalización y tramado de interfaz - de las imágenes no sólo las remueve de su, hasta ahora, irremediable estatus de "obstáculo epistemológico", sino que las convierte en ingrediente clave de un nuevo tipo de relación entre la simulación y la experimentación científica (Lévy).

La actual revaloración cognitiva de la imagen pasa paradójicamente por la crisis de la representación tematizada por Michel Foucault (1966) a partir de la trama significante que tejen las figuras y los discursos (las imágenes y las palabras) y de la eficacia operatoria de los modelos que hacen posible ese saber que hoy denominamos ciencias humanas. Es justamente en el cruce de los dos dispositivos señalados por Foucault —economía discursiva y operatividad lógica— donde se sitúa la nueva discursividad constitutiva de la visibilidad y la nueva identidad lógico-numérica de la imagen. Estamos ante la emergencia de una “nueva figura de razón” (Renaud) que exige pensar la imagen, de una parte, desde su nueva configuración socio-técnica —el computador inaugurando un tipo de tecnicidad que posibilita el procesamiento de informaciones, y cuya materia prima son abstracciones y símbolos - y de otra, la emergencia de un nuevo paradigma del pensamiento que rehace las relaciones entre el orden de lo discursivo (la lógica) y lo visible (la forma), de la inteligibilidad y la sensibilidad. El nuevo estatuto cognitivo de la imagen se produce a partir de su informatización, es decir, de su inscripción en el orden de lo numerizable, que es el orden del cálculo y sus mediaciones lógicas: número, código, modelo. Inscripción que remite, sin embargo, no sólo a una economía informacional (Chartron) sino a una ironía de lo figural (Levin, Lenain) en las que la imagen deja de tener como lastre su errancia estética y su complicidad con la seducción.

El proceso que ahí llega entrelaza un doble movimiento. El que prosigue y radicaliza el proyecto de la ciencia moderna — Galileo, Newton — de traducir/sustituir el mundo cualitativo de las percepciones sensibles por la cuantificación y la abstracción lógiconumérica, y el que reincorpora al proceso científico el valor informativo de lo sensible y lo visible. Una nueva episteme cualitativa abre la investigación a la intervención 
constituyente de la imagen en el proceso del saber: arrancándola a la sospecha racionalista, la imagen es percibida por la nueva episteme como posibilidad de experimentación/ simulación que potencia la velocidad del cálculo y permite inéditos juegos de interfaz, es decir, arquitecturas de lenguaje. Paul Virilio denomina "logística visual” a la remoción que las imágenes informáticas hacen de los límites y funciones tradicionalmente asignados a la discursividad y la visibilidad, a la dimensión operatoria (control, cálculo y previsibilidad), la potencia interactiva (juegos de interfaz) y la eficacia metafórica (traslación del dato cuantitativo a una forma perceptible: visual, sonora, táctil). La visibilidad de la imagen deviene legibilidad (Lascaut), que permite pasar del estatuto de “obstáculo epistemológico” al de mediación discursiva de la fluidez (flujo) de la información y del poder virtual de lo mental.

> DES-UBICACIONES Y REUBICACIONES DE LA LETRA

Así como el computador nos coloca ante un nuevo tipo de tecnicidad, nos hallamos también ante un tipo de textualidad que no se agota en el computador; el texto electrónico se despliega en una multiplicidad de soportes y escrituras que, de la televisión al videoclip y del multimedia a los videojuegos, encuentran una compleja y creciente complicidad entre la oralidad y la visualidad de los más jóvenes. Es en las nuevas generaciones donde esa complicidad opera más fuertemente, no porque los jóvenes no sepan leer o lean poco, sino porque su lectura ya no tiene al libro como eje y centro de la cultura. Es la noción misma de lectura la que está en cuestionamiento: la que al quedarse sin su centro estalla, obligándonos a pensar el desorden estético que introducen las escrituras electrónicas y la experiencia audiovisual. Pues la visualidad electrónica ha entrado a formar parte constitutiva de la visibilidad cultural, esa que es a la vez entorno tecnológico y nuevo imaginario “capaz de hablar culturalmente —y no sólo de manipular tecnológicamente—, de abrir nuevos espacios y tiempos para una nueva era de lo sensible” (Vattimo, 1989).

Una de las más claras señales de la hondura de las mutaciones que atravesamos se halla en la reintegración cultural de la dimensión separada y minusvalorada por la racionalidad dominante en Occidente desde la invención de la escritura y el discurso lógico, esto es, la del mundo de los sonidos y las imágenes relegado al ámbito de las emociones y las expresiones. Al trabajar interactivamente con sonidos, imágenes y textos escritos, el hipertexto (Landow, Laufer) hibrida la densidad simbólica con la abstracción numérica haciendo que se reencuentren las dos, hasta ahora “opuestas”, partes del cerebro. De ahí que de mediador universal del saber, el número esté pasando a ser mediación técnica del hacer estético, lo que a su vez revela el paso de la primacía sensorio-motriz a la sensorio-simbólica. Es de esa reintegración y ese tránsito que habla la des-ubicación que hoy atraviesa el arte. El acercamiento entre experimentación tecnológica y estética hace emerger, en este desencantado fin de siglo, un nuevo parámetro de evaluación de la técnica, distinto al de su mera instrumentalidad económica o su funcionalidad política: el de su capacidad de comunicar, esto es, de significar las más hondas transformaciones de época que experimenta nuestra sociedad, y el de desviar/subvertir la fatalidad destructiva de una revolución tecnológica prioritariamente dedicada, directa o indirectamente, a acrecentar el poderío militar. 
La gramática de construcción de los nuevos relatos se alimenta del zapping y desemboca en el hipertexto, lo que implica un doble y muy distinto movimiento que la reflexión crítica tiende a confundir anulando las contradicciones que los ligan. La gramática narrativa predominante dicta una clara reducción de los componentes propiamente narrativos (Sánchez-Biosca) — ausencia o adelgazamiento de la trama, acortamiento de las secuencias, desarticulación y amalgama-, la prevalencia del ritmo sobre cualquier otro elemento con la consiguiente pérdida de espesor de los personajes, el pastiche de las lógicas internas de un género con las de otros — como los de la estética publicitaria o la del videoclip — y la hegemonía de la experimentación tecnológica, cuando no la de la sofisticación de los efectos sobre el desarrollo mismo de la historia. El estallido del relato, y la preeminencia del flujo de imágenes que ahí se producen, encuentran su expresión más certera en el zapping con el que el televidente, al mismo tiempo que multiplica la fragmentación de la narración, construye con sus pedazos un relato otro puramente subjetivo, intransferible, una experiencia incomunicable. Estaríamos acercándonos al final del recorrido que Walter Benjamin vislumbró al leer en el declive del relato la progresiva incapacidad de los hombres para compartir experiencias. Pero ese movimiento de estallido y fragmentación desembocó también sobre la potenciación de otro movimiento, en el que el mismo Benjamin atisbó el surgimiento de aquella narrativa a la que tendía el nuevo sensorium de la dispersión y la imagen múltiple: el del montaje cinematográfico precursor, como el montaje textual del Ulises de Joyce, de la narrativa hipertextual (Delany y Landow): "La línea de la cultura se ha quebrado, y también lo ha hecho con ella el orden temporal sucesivo. La simultaneidad y la mezcolanza han ganado la partida: los canales se intercambian, las manifestaciones cultas, las populares y las de masas dialogan y no lo hacen en régimen de sucesión, sino bajo la forma de un cruce que acaba por tornarlas inextricables” (Renaud 199514 y ss). El estallido del orden sucesivo lineal alimenta un nuevo tipo de flujo que conecta la estructura reticular del mundo urbano con la del texto electrónico y el hipertexto. En la asunción de tecnicidad mediática como dimensión estratégica de la cultura puede nuestra sociedad interactuar con los nuevos campos de experiencia en que hoy se procesan los cambios: desterritorialización/ relocalización de las identidades, hibridaciones de la ciencia y el arte, de las escrituras literarias, audiovisuales y digitales, la reorganización de los saberes desde los flujos y redes por los que hoy se moviliza no sólo la información sino el trabajo y la creatividad, el intercambio y la puesta en común de proyectos políticos, de investigaciones científicas y experimentaciones estéticas. Interactuar tanto con las nuevas figuras y modalidades de la profesión como con las nuevas formas de participación ciudadana que ahí se le abren especialmente a la vida local. 
BIBLIOGRAFIA

Anceschi, Giovanni. Videoculturas de fin de siglo. Madrid: Cátedra, 1996.

Appadurai, Arjun. La modernidad desbordada: demensiones culturales de la globalización. Montevideo, Uruguay: Ediciones Tricle, 2001.

Arendt, Hannah. La condición humana. Barcelona: Ediciones Paidós, 1993.

Bauman, Zygmunt y Daniel Zadunaisky. La globalización: consecuencias humanas. México: Fondo de Cultura Económica, 2001.

Beck, Ulrich y Bernardo Moreno Carrillo. Un nuevo mundo feliz: la precariedad del trabajo en la era de la globalización. Barcelona: Paidós, 2000.

Bellah, Robert Neelly. Habits of the Heart: Individualism and Commitment in American Life. Berkeley: University of California Press, 1985.

Bhabha, Homi K. Nation and narration. London; New York: Routledge, 1990.

Bonin, Pierre-Yves. Mondialisation: perspectives philosophiques. Paris; Québec: Presses de l’Université Laval-Harmattan, 2001.

Braganca, J.A. y M.T. Torres. Crítica das ligações na Era da Técnica. Porto Alegre: Tropismos, 2001.

Broncano, Fernando. Mundos artificiales: filosofía del cambio tecnológico. México: Paidós-UNAM, 2000.

Castells, Manuel. La Era de la información: economía, sociedad y cultura. México : Siglo Veintiuno Editores, 2001.

Chartron, Ghislaine. Pour une nouvelle économie du savoir. Rennes: Presses Univ. de Rennes, 1994.

Delany, Paul y George Landow (Eds.) Hypermedia and Literary Studies. Cambridge: MIT, 1991.

Drucker, Peter. La sociedad postcapitalista. Buenos Aires: Sudamericana, 1999.

Dubar, Claude. La crise des identités: L'interprétation d'une mutation. París: PUF, 2000.

Echeverría, Javier. Los señores del aire: Telépolis y el tercer entorno. Barcelona: Destino, 1999.

Ciencia y valores. Barcelona: Destino, 2002.

Finquelievich, Susana. ¡Ciudadanos a la red! Los vínculos sociales en el ciberespacio. Buenos Aires: Ciccus-La Crujía, 2000.

Fischer, Hervé. Le choc numerique. Montreal: Vlb Editor, 2001.

Flichy, Patrice. L'imaginaire d'Internet. Paris : Découverte, 2001.

Flores d'Arcais. El individuo libertario. Recorridos de filosofía moral y política en el horizonte de lo finito. Barcelona: Seix Barral, 2001.

Fraser, Nancy. "Redistribución y reconocimiento”. Justicia interrupta. Reflexiones críticas desde la posición 'postsocialista'. Bogotá: Siglo del Hombre, 1998.

Foucault, Michel. Les mots et les choses; une archéologie des sciences humaines. Paris: Gallimard. 1996.

Giddens, Anthony. Consecuencias de la modernidad. Madrid : Alianza Editorial, 1993.

Gombrich, E H, Didier Eribon y Rubén Sierra Mejía. Lo que nos dice la imagen: conversaciones sobre el arte y la ciencia. Barcelona, Santafé de Bogotá: Grupo Editorial Norma. 1993. 
Grimson, Alejandro y Roberto Cardoso de Oliveira. Fronteras, naciones e identidades: la periferia como centro. Buenos Aires: Ediciones CICCUS-Ediciones La Crujía, 2000.

Habermas, Jürgen. El discurso filosófico de la modernidad: doce lecciones. Madrid: Taurus-Santillana. 1993.

Hall, Stuart. A identidade cultural na postmodernidade. Río de Janeiro: D.P.\& Editora, 1999.

Harvey, David. The Condition of Postmodernity: An Enquiry into the Origins of Cultural Change. Oxford [England]; Cambridge, Mass., USA: Blackwell. 1989.

Huyssen, Andreas. After the Great Divide: Modernism, Mass Culture, Postmodernism. Bloomington: Indiana University Press. 1986.

“La cultura de la memoria”. Revista de Crítica Cultural 18 (1999). Memórias do modernismo. Rio de Janeiro: UFRJ, 1997.

Twilight Memories: Parking Time in a Cultura of Amnesia. New York: Routledge, 1995.

Klein, Naomi. No logo: el poder de las marcas. Barcelona; Buenos Aires; México: Paidós, 2001.

Kroes, Rob. Ciudadanía y globalización: Europa frente a Norteamérica. Madrid: Cátedra, 2000.

Kymlicka, Hill. Ciudadanía multicultural: una teoría liberal de los derechos de las minorías. Barcelona: Paidós, 1996.

Laclau, Ernesto. Emancipación y diferencia. Buenos Aires: Ariel, 1996.

Landow, George P. Hipertexto: la convergencia de la teoría crítica contemporánea y la tecnología. Barcelona: Paidós, 1995.

Laufer, Roger y Domenico Scavetta. Texte, hypertexte, hypermedia. Paris: Presses Universitaires de France, 1992.

Lechner, Norbert. “América Latina: la visión de los cuentistas sociales”. Nueva Sociedad 139 (Caracas, 1995).

Lenain, Thierry. L'image: Deleuze, Foucault, Lyotard. Paris: J. Vrin, 1997.

Lévy, Pierre. Les technologies de l'intelligence. Paris: La Découverte, 1990. Cyberculture: rapport au conseil de l'Europe dans le cadre du projet "Nouvelles technologies: coopération culturelle et communication”. Paris: Ed. O. Jacob, 1997.

Levin, David Michael. Modernity and the Hegemony of Vision. Berkeley: University of California Press, 1993.

Lotman, IU M y Jorge Lozano. Semiótica de la cultura. Madrid: Ediciones Cátedra, 1997. Maffesoli, Michel. La Contemplation du monde: figures du style communautaire. Paris: B. Grasset, 1993.

Marinas, José Miguel. "La identidad cortada”. Archivos de la filmoteca, Monográfico: “Destinos del relato al filo del milenio". Filmoteca de la Comunidad Valenciana, 1996.

Marramao, Giacomo, Juan Ramón Capella y Salvador Giner. Poder y secularización. Barcelona: Península, 1989. 
Meyrowitz, Joshua. No sense of place: the impact of electronic media on social behavior. New York: Oxford University Press, 1985.

Molina, José Luis. El análisis de redes sociales: una introducción. Barcelona: Ediciones Bellaterra, 2001.

Mongin, Olivier. Face au scepticisme: les mutations du paysage intellectuel (1976-1998) Paris: Hachette Littératures, 1998.

Mouffe, Chantal. El retorno de lo político: comunidad, ciudadanía, pluralismo, democracia radical. Barcelona; Buenos Aires; México: Paidós, 1999.

"Por una política de la identidad nómada". Debate feminista 14 (1996).

Renaud, Alain. "De l'e economie informationelle á la pensée visuelle”. Reseaux 74 (1995).

Rifkin, Jeremy, J Francisco Álvarez y David Teira. La era del acceso: la revolución de la nueva economía. Barcelona; Buenos Aires; México: Paidós, 2000.

Sánchez-Biosca, Vicente. Una cultura de la fragmentación: Pastiche, relato y cuerpo en el cine y la televisión. Valencia: Filmoteca de la Generalitat Valenciana, 1995.

“Postmodernidad y relato: el trayecto elctrónico". TELOS 16 (1989).

Sarlo, Beatriz. "Ya nada será igual”. Punto de vista 70 (2000).

Senté, Richard. A corrosao do character. Consecuencias pessoais do trabalho no novo capitalismo. Río de Janeiro: Record, 1999.

Sosoe, Lukas K y otros. Diversité humaine: démocratie, multiculturalisme et citoyenneté. Sainte-Foy, Québec: Paris: Presses de l’Université Laval; L’Harmattan, 2002.

Taylor, Charles. Multiculturalismo: la politica del riconoscimento. Milano: Anabasi, 1993.

Touraine, Alain. Critique de la modernité. Paris: Fayard, 1992.

Varela, Francisco J y otros. De cuerpo presente: las ciencias cognitivas y la experiencia humana. 2da ed. Barcelona: Gedisa, 1997.

Vattimo, Gianni . El fin de la modernidad: nihilismo y hermenéutica en la cultura posmoderna. Barcelona: Editorial Gedisa, 1987.

Más allá del sujeto: Nietzsche, Heidegger y la hermenéutica. Barcelona: Ediciones Paidos, 1989.

La sociedad transparente. Barcelona: Ediciones Paidós-I.C.E. de la Universidad Autónoma de Barcelona, 1990.

Vidal Beneyto, José. La ventana global. Ciberespacio, esfera pública mundial y universo mediático. Madrid: Taurus-UNESCO, 2002.

Virilio, Paul y Mariano Antolín Rato. La máquina de visión. Madrid: Cátedra, 1989. L'art du moteur. Paris: Editions Galilée, 1993.

Wieviorka, Michel y François Dubet. Une société fragmentée?: le multiculturalisme en débat. Paris: La Découverte, 1997. 